To Cite This Article: Kesgin Atak, B. (2020). Analysing the relationships between land use/land cover and urban land surface temperature using regression tree in İmir. International Journal of Geography and Geography Education (IGGE), 41, $280-291$.

\title{
ANALYSING THE RELATIONSHIPS BETWEEN LAND USE/LAND COVER AND URBAN LAND SURFACE TEMPERATURE USING REGRESSION TREE IN IZMIR
}

Birsen KESGIN ATAK ${ }^{1}$

\begin{abstract}
Quantitative analysis of the effects of different land use/land cover (LULC) types on the urban heat island (UHI) formation is very critical for urban planning. The UHI is typically characterized by land surface temperature (LST) through the use of airborne or satellite thermal infrared remote sensing. In this context, this research aims to determine urban heat island formation in Izmir by calculating LST value and to evaluate the relationship between LST values and LULC classes and their sizes using regression tree analyses. The main materials of the analyses are composed of three cloud free Landsat 8 images for the hottest summer period in Izmir as well as the Urban Atlas 2012 data set. The results showed that LST values were increased with the increasing proportion of artificial surfaces and decreasing the presence of vegetation and water for the selected three months. It is also found that there is a strong positive correlation between the LST values and mine, dump and construction sites. This research showed that such land uses not only destruct the natural and cultural landscape elements, but also increase the land surface temperature and adversely affect the urban climate regardless of their sizes in the whole landscape.
\end{abstract}

Keywords: Land Surface Temperature, Land Use/Land Cover, Regression Tree Analyses, Urban Heat Island

\footnotetext{
${ }^{1}$ Assist Prof., Aydın Adnan Menderes University, Faculty of Agriculture, Department of Landscape Architecture, Aydın/TURKEY., http://orcid.org/O0000003-4786-0801., birsenatak@adu.edu.tr
} 


\section{INTRODUCTION}

Land use/land cover (LULC) changes are consired among the most important landscape indicators that reflect humanenvironment interactions which negatively affect the climatic system. Driven by exponential population growth, land use/land cover dynamics has been significantly changing in urban and rural areas (Valsson and Bharat, 2009). Depending on residential, commercial and industrial developments, urbanisation is considered to be an important factor in LULC changes at all temporal and spatial scales. Urbanisation is also considered to be the most important factors that affect the temperature in urban center and its surroundings ( $\mathrm{Pal}$ and Ziaul, 2017; Ersoy, 2019). The climatic variation between cities and their surrounding rural regions is defined as the urban heat island (UHI) (Oke, 1973). The UHI is an urban microclimate that is generally caused by LULC changes in urban areas (Akbari and Kolokotsa, 2016; Feizizadeh et al., 2013) and it is one of the best-known forms of local climate change caused by human activities (Oke, 1973; Montávez et al., 2000). The concept of urban heat islands was first identified by Luke Howard in London in 1820 and has been included in the literature (Streutker, 2003). One of the earliest studies about the UHI has been held in urban parts of southern Singapore in 1964 by Nieuwolt (1966) (Pal and Ziaul, 2017).

Urbanisation has many faces that impact the changes in thermal environment. Urban structure and characteristics, (morphology, macroform, green system, urban texture, building compositions etc), urban surface response (such as surface characteristics including roads, impervious surface area or building density and height and surface materials whose thermal properties differ from the surrounding rural environment are some important factors (Stone and Norman, 2006; Hart and Sailor, 2009; Pal and Ziaul, 2017). The use of surface materials like concrete, asphalt, bricks, stones, tiles in urban areas increases the amount of dark surface and the resulting solar radiation is absorbed and emitted much more than reflection. Dense and high-rise buildings cause increased levels of heat absorption as well as inreased temperature. Clearing natural and semi-natural vegetation, the destruction of forests in urban areas cause the natural greenhouse effect by the reduction of trees and plants holding and storing carbon dioxide. Additionally, the conversion of natural and semi-natural land cover types into high density buildings alter the land surface energy processes (Voogt and Oke, 2003; EPA, 2012).

Literature states that urban heat islands have negative effects on increasing energy consumption (Santamouris et al., 2015), and reducing air and water quality (Zhao et al., 2016). The higher temperatures in urban heat islands increase pollution levels, energy consumption and may negatively affect precipitation patterns which may pose a significant threat to living organisms (Alghannam and Al-Qahtnai, 2012). On the other hand, recent studies indicate that the areas covered with vegetation in urban areas have lower temperatures than the permeable and bare surfaces around them and the structural areas (Pal and Ziaul, 2017; Xiao et al., 2018). Considering all of these, an understanding of the driving factors related to the formation of UHI and their relationships with differentLULC types are critical to improve urban living conditions and to create a new perception of the future city. Such an understanding is of great importance in the development of planning approaches to reduce urban microclimate.

The LST is a critical index to understand the relationships between the urbanisation pattern and the thermal environment. Therefore, in recent years the LST has been frequently used in UHI studies to understand the relationships between the LST and different LULC types (Schwarz et al., 2012; Du et al., 2016; Zhou et al., 2014; Şimşek and Şengezer, 2012; Tonyaloğlu, 2019) as well as determining the influences of the composition and configuration of the certain green spaces; such as parks, gardens and green roofs; on the LST (Zhou et al., 2017; Klein and Coffman, 2015). In literature, various satellite images have been used to calculate the LST values for different purposes such as; the Advanced Very HighResolution Radiometer (AVHRR) on the NOAA 7 satellite (Price, 1984; Sobrino et al., 2004), MODIS (Tran et al., 2006; Wan et al., 2004; Yavaşli et al.,2018) and ASTER sensor products (Jimenez and Sobrino, 2010; Oguz, 2015). As being one of the most common satellites, Landsat TM and Enhanced Thematic Mapper Plus (ETM+) and LANDSAT 8 OLI images have been used in research related to the surface temperature characteristics of urban areas. (Sobrino et al., 2004; Weng et al., 2004; Şahin et. al., 2011; Oguz, 2013; Rozenstein et al., 2014; Reddy and Manikiam, 2017).

It is emphasised that the presence of vegetation and especially the abundance and density of vegetation is one of the most important factors in reducing the negative effects of UHIs (Weng et al., 2004; Huang et al., 2008). In this context, various vegetation indices are obtained by using remote sensing techniques and used for the evaluation of vegetation. Thermal remote sensing studies show that the normalized difference vegetation index (NDVI) is one of these indices that is widely used for the identification of vegetation (Yuan and Bauer, 2007).

Due to the socio-economic development Izmir is one of the most rapidly growing city in Turkey (Nurlu et al., 2015). As a result of the rapid urbanisation, the large volume of the human population causes increasing energy consumption, the development of dense urban infrastructure which significantly affects the quality of life of urban inhabitants, and the aggravated urban environments and urban climate. In addition to that, the extreme heat waves are one of the major problems in İzmir (Aydın et al., 2017). The dense construction pattern in the city center inhibits the cooling winds from 
the Aegen Sea and results in its inhabitants to be affected more by the heat waves. Therefore, understanding which LULC types in urban landscape change the surface temperature? and does the size of different LULC types affect the surface temperature? became important question to ask to reduce UHI affect and take a preucation for urban action plans. In this contex, this research aims to evaluate the relationships between different LULC types and LST patterns in Izmir during summer months. The research was carried out in 3 main stages: 1) reclassification of the LULC types which are obtained from the urban atlas 2012 dataset 2) deriving the LST values and analysing their spatial variations using Landsat 8 thermal bands in the hottest summer period (19 June, 21 July and 22 August 2013, respectively) in İzmir, and 3) evaluating the relationships between the LST and different LULC types based on a regression tree analysis.

Although, there are many research on literature to analyse relationbship between LST and just LULC types (Zhou et al., 2014; Xiao et al., 2018), in this case, additionally the UHI develpment mechanism, the effects of land use type, patch size and neighourhood relationship has been evaluated using decision tree algorithms in the case of izmir. In our country, decision tree algorithms are quite new in the field of landscape researchs. The most important advantage of decision tree algorithms is that the statistical assumptions, as in other multivariate techniques, do not exist in this method. Another advantage is that the decision tree algorithms visualise the direction and importance of relationships between LST (dependet variebles) and size and category of LULC types (independent variables).

\section{MATERIAL AND METHOD}

\section{Study Area}

The study area covers 11 districts within the boundaries of the Izmir Metropolitan Municipality, where the intense urbanisation with the high development of the coastal districts: Bornova, Buca, Gaziemir, Karabağlar Çiğli, Karşıyaka, Bayraklı, Konak, Balçova, Narlıdere, and Güzelbahçe (Figure 1). The study area covers 95,880 ha with a population of 2.815.215 people in 2013 according to the Address Based Population Registration System (ADNKS). Almost 68\% of the province's population lives in the study area and it is increased to 2.914.408 in 2018 (TUIK, 2019). Because of its location, appropriate topographic structure and climatic conditions, İzmir is becoming a center of attraction throughout the country.

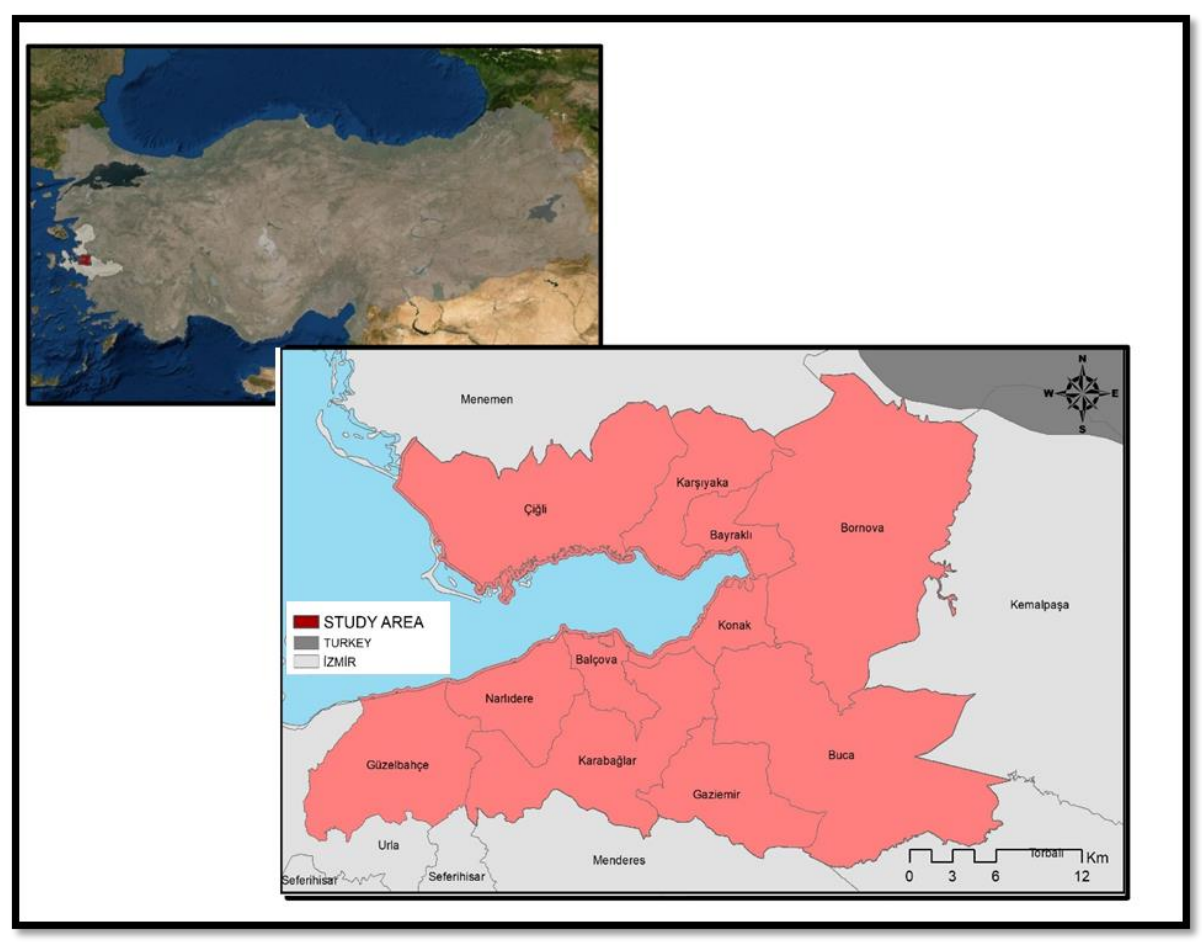

Figure 1: Location of the Study Area

Izmir is characterised by the Mediterranean climate with long, hot and dry summers, and mild to cool, rainy winters. The average annual temperature is $18.5^{\circ} \mathrm{C}$ and the annual precipitation is $854.7 \mathrm{~mm}$. In summer periods, the temperature in the coastal parts of Izmir receives the sea breeze (imbat) with a temperature lowering effect of $1-2^{\circ} \mathrm{C}$ compared to its inner parts. In winter, the average temperature of $9{ }^{\circ} \mathrm{C}$ falls from time to time due to the mass of marine air from the 
north and northwest. The average temperature in January was $9.4{ }^{\circ} \mathrm{C}$ in Izmir; In July it is $28.4{ }^{\circ} \mathrm{C}$ (Table 1). Whilst the highest temperature of $43.0^{\circ} \mathrm{C}$ in Izmir (1938 - 2018) was measured on 12.08 .2002 ; the lowest temperature of $-8.2^{\circ} \mathrm{C}$ was measured on 04.01.1942. The coldest months in the province are January and February, and the hottest months are June, July and August.

\begin{tabular}{|c|c|c|c|c|c|c|c|c|c|c|c|c|}
\hline Months & 1 & 2 & 3 & 4 & 5 & 6 & 7 & 8 & 9 & 10 & 11 & 12 \\
\hline The average temperature $\left({ }^{\circ} \mathrm{C}\right)$ & 9.4 & 11.2 & 14.0 & 17.3 & 22.7 & 25.7 & 28.4 & 28.7 & 24.0 & 17.2 & 15.0 & 8.5 \\
\hline
\end{tabular}

\section{Data Used in this Study}

In order to calculate the NDVI and LST values, 3 cloudless Landsat 8 OLI (Operational Land Imager) images were obtained from the USGS website for this study. The hottest period of Izmir has been taken into consideration to discriminate the natural vegetation and artificial surfaces in LULC classes. The acquisition dates of Landsat 8 OLI images were 19 June 2013, 21 July 2013 and 22 August 2013 (USGS, 2018). The LST values were calculated using the 100m spatial resolution Landsat $8 \mathrm{OLI}$ (Operational Land Imager) thermal infrared (TIR) bands (Band10 and Band11). Additionally, the nearinfrared and red bands were used to calculate NDVI values (Table 2). In order to determine the relationships between the LST and different LULC types, the European Urban Atlas 2012 data downloaded from Copernicus Land Observation Services website (CLMS, 2018). The statistical calculations were performed in SPSS 17.0 software.

\begin{tabular}{|lll|}
\hline & Table 2: Landsat 8 Bands Used in This Research (USGS, 2018) \\
\hline Bands & $\begin{array}{l}\text { Wavelength } \\
\text { (micrometers) }\end{array}$ & $\begin{array}{l}\text { Resolution } \\
\text { (meters) }\end{array}$ \\
\hline Band 4- Red & $0.64-0.67$ & 30 \\
Band 5- Near Infrared & $0.85-0.88$ & 30 \\
Band 10- Thermal Infrared (TIRS) 1 & $10.60-11.19$ & 100 \\
Band 11- Thermal Infrared (TIRS) 2 & $11.50-12.51$ & 100 \\
\hline
\end{tabular}

\section{Calculation of Land Surface Temperature (LST)}

In this study, the LST method was used to determine the UHI formation in urban areas. The LST has been calculated according to the method previously applied by Chen et al. (2014) and Du et al. (2017). The research method consists of 5 stages (Figure 2).

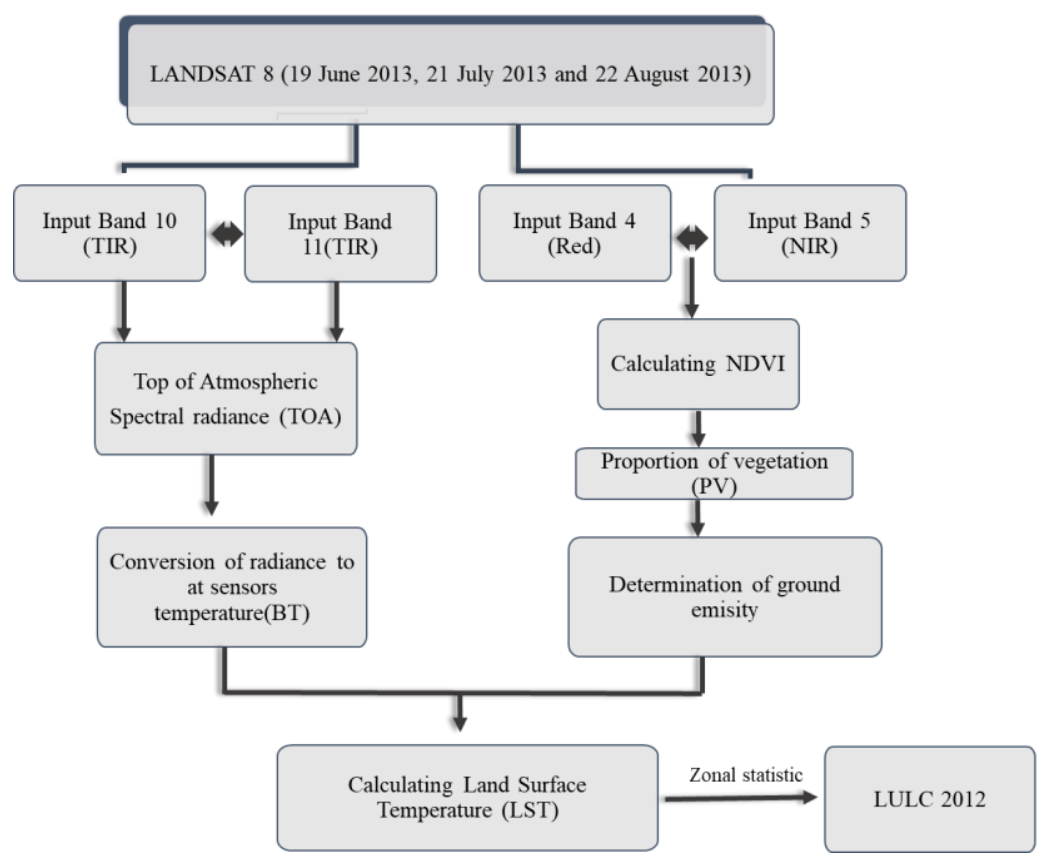

Figure 2: Flow Chart of this Research

Initially, all the bands of Landsat 8 images and LULC maps were resampled to the same size, resolution, extend and projection (WGS 1984 UTM Zone 35N). The thermal bands of the Landsat 8 satellite images were resampled with the nearest neighboring algorithm at a $30 \mathrm{~m}$ spatial resolution. The LULC map was converted to the same coordinate system 
and resampled with the same resolution $(30 \mathrm{~m})$ and clipped according to the boundaries of the study area. The data used in the LST analysis were obtained from the metadata file of each image.

\section{Calculation of the Top of Atmospheric Radiance (TOA)}

In order to obtain the LST information, the following operations were applied. First, the brightness values (0-255) were converted to the spectral radiance (SR) values using thermal infrared bands (TIR) (band 10 and band 11) (USGS, 2018). The following equation was used (Eq. 1) (Chander and Markham, 2003):

$$
L_{\lambda}=\left(\frac{L_{M A X \lambda}-L_{M I N \lambda}}{Q_{\text {CalMAX }}-Q_{\text {CalMIN }}}\right)\left(D N-Q_{\text {CalMIN }}\right)+L_{M I N \lambda}
$$

$\mathrm{L} \lambda$ is TOA radiance at the sensor's aperture in Watt/(m2 sr $\mu \mathrm{m}), \mathrm{QCALmax}(=255)$ and QCALmin $(=0)$ are the highest and the lowest points of the range of rescaled radiance in DN (given in the header file of the images), Lmin and Lmax are the TOA radiances that are scaled to QCALmin and QCALmax in W/(m2 sr $\mu \mathrm{m})$.

Then, based on the equation below, the effects of the atmosphere in the thermal region were removed and TOA radiance was converted to the surface-leaving radiance (Eq. 2 ) (Barsi et al., 2005):

$$
L_{\lambda}=M_{L} * Q_{\text {Cal }}+A_{L}
$$

$\mathrm{L} \lambda$ is TOA radiance at the sensor's aperture in Watt/(m2 sr $\mu \mathrm{m}), \mathrm{ML}$ is band specific multipicative rescalling factor from metadata (which is 0,0003342 for band 10 and band 11), AL is band specific additive rescalling factor from metadata file of the images (which is 0.1 for band 10 and band 11 ) ,Qcal is actual digital number of the thermal band (standart product pixel value)

\section{Transformation of Spectral Radiance to Blackbody Temperature (BT)}

In the second stage, the spectral radiance values were converted to the reflectance values. The radiance values were then converted to the satellite brightness temperature (BT) in ${ }^{\circ} \mathrm{C}$ using the Landsat specific estimate of the Planck curve (Eq. 3) (Chander and Markham, 2003; USGS, 2018). The conversion formula is:

$$
B_{T}=\left(\frac{K_{2}}{\ln \left(\frac{K_{1}}{L_{\lambda}}\right)}+1\right)-273.15
$$

Where BT is satellite brightness temperature in Kelvin $(K), L \lambda$ is the top of atmospheric radiance in Watt/(m2 sr $\mu \mathrm{m})$, $\mathrm{K} 1$ and $\mathrm{K} 2$ band specific thermal calibration constant from metafile of the images (for LANDSAT 8 band $10 \mathrm{~K} 1=774.88 \mathrm{~K}$, $\mathrm{K} 2=1321.07 \mathrm{~K}$ for band11, $\mathrm{K} 1=480.88 \mathrm{~K}$, and $\mathrm{K} 2=1201.14 \mathrm{~K}$.

\section{Determination of Land Surface Emmisivitiy (LSE)}

Land surface emissvity $(\varepsilon)$ was determined by calculating the vegetation index NDVI (Normalized difference vegetation index) using the red and near infrared bands of the Landsat image (Eq. 4):

$$
N D V I=\frac{N I R-R}{N I R+R}
$$

Where NIR and R are the spectral reflectances in the TM and ETM+ near-infrared bands and red bands respectively. This NDVI values in the range from -1 to 1 , when values approach to +1 which represent healty vegetated areas and when values approach to -1 which indicate that non-vegetated, bared surface or water, clouds, and snow.

The NDVI maps were derived for all the three dates. Then, in order to determine the ground (surface) emissivity, the proportion of vegetation (Pv) was calculated using the following equation (Eq. 5).

$$
P_{v}=\left(\frac{N D V I-N D V I_{\min }}{N D V I_{\max }-N D V I_{\min }}\right)^{2}
$$

\section{Determination of land Surface Temperature (LST)}

Finally, the LST was determined using the formulas below (Eq. 6 and 7);

$$
\begin{gathered}
\varepsilon=0.004 * P_{v}+0.986 \\
L S T=\frac{B T}{1+\left(\frac{w * B T}{p}\right) * \ln _{(\varepsilon)}}
\end{gathered}
$$

BT is is satellite brightness temperature in Kelvin, $p=h^{*} c / s$ ( $h$ is the Planck's constant (6.626_10_34 J s), $c$ is the velocity 
of light $\left(2.998 \_108 \mathrm{~m} / \mathrm{s}\right), \mathrm{s}$ is the Boltzmann constant $\left.\left(1.38 \_10 \_23 \mathrm{~J} / \mathrm{K}\right)\right), \mathrm{w}$ is the wavelenght of emmited radiance $(11,5$ $\mu \mathrm{m}$ is used (Markham and Barker, 1985), $\varepsilon$ is land surface emmisivity value.

\section{Land Use/Land Cover Map}

The LULC map of Izmir was obtained from the European Urban Atlas data (EEA, 2012). The 27 subclasses of the Urban Atlas 2012 data were reclassified into 10 LULC types described in Table 3.

\begin{tabular}{|c|c|c|}
\hline LULC Classess & Description (UA CODE) & Class Code/Original Urban Atlas Data Class \\
\hline 1 & Urban Fabric (1.1) & $\begin{array}{l}11100 \text { Continuous urban fabric (S.L.: >80\%)11210 Discontinuous dense urban } \\
\text { fabric (S.L.: } 50-80 \%) ; 11220 \text { Discontinuous medium density urban fabric; } \\
11230 \text { Discontinuous low density urban fabric (S.L.: } 10-30 \%) ; 11240 \\
\text { Discontinuous very low density urban fabric (S.L.: }<10 \%) ; 11300 \text { Isolated } \\
\text { structures; } 12300 \text { Port areas30-50\%) }\end{array}$ \\
\hline 2 & $\begin{array}{l}\text { Industrial, commercial, public, military, private } \\
\text { and transport units (1.2) }\end{array}$ & $\begin{array}{l}12100 \text { Industrial, commercial, public, } 12220 \text { Other roads and associated land; } \\
12230 \text { Railways and associated land; } 12400 \text { Airports }\end{array}$ \\
\hline 3 & Mine, dump and construction sites (1.3) & 13100 Mineral extraction and dump sites;13300 Construction sites \\
\hline 4 & Artificial non-agricultural vegetated areas (1.4) & $\begin{array}{l}13400 \text { Land without current use; } 14100 \text { Green urban areas; } 14200 \text { Sports and } \\
\text { leisure facilities }\end{array}$ \\
\hline 5 & Agricultural areas (2) & $\begin{array}{l}21000 \text { Arable land (annual crops); } 22000 \text { Permanent crops (vineyards, fruit } \\
\text { trees, olive groves); } 23000 \text { Pastures }\end{array}$ \\
\hline 6 & Forests (3.1) & 31000 Forest \\
\hline 7 & $\begin{array}{l}\text { Herbaceous vegetation associations (natural } \\
\text { grassland, moors...) (3.2) }\end{array}$ & $\begin{array}{l}32000 \text { Herbaceous vegetation associations (natural grassland, moors...);33000 } \\
\text { Open spaces with no or little vegetation }\end{array}$ \\
\hline 8 & Wetlands (4) & 4000 Wetlands \\
\hline 9 & Water (5) & 5000 Water \\
\hline 10 & No data (Clouds and shadows) & 92000 No data \\
\hline
\end{tabular}

General distrubition of area of LULC categories in Izmir are given in Table 4. In 2012, herbaceous vegetation associations (26.42 \%) and forest (23.82 \%) are covered the highest proportion of the landscape. This was followed by agricultural areas, industrial, commercial, public, military, private and transport units and urban fabric. The proportion of the landscape occupied by mine, dump and construction sites and Wetlands are quite low (a total of $2.34 \%$ and 1.09 of the landscape, respectively).

\begin{tabular}{|llll|}
\hline \multicolumn{2}{c|}{ Table 4: Description of Mapping Units for the Urban Atlas Land Use/Land Cover (LULC) } \\
\hline & LULC & Number of patch & Area (Ha) \\
\hline 1 & Urban Fabric & 17137 & 9748.15 \\
2 & Industrial, commercial, public, military, private* & 5133 & 11873.54 \\
3 & Mine, dump and construction sites & 1056 & 2010.87 \\
4 & Artificial non-agricultural vegetated areas & 893 & 1574.17 \\
5 & Agricultural areas & 1144 & 12724.86 \\
6 & Forests & 653 & 20494.72 \\
7 & Herbaceous vegetation associations & 1014 & 22733.95 \\
8 & Wetlands & 9 & 935.74 \\
9 & Water & 85 & 3879.01 \\
10 & No data & 11 & 23.83 \\
\hline
\end{tabular}

\section{Statistical Analyses}

The relationships between the LST and different LULC types were determined and evaluated using the zonal statistics tool in ArcGIS. Then, the regression tree analysis in SPSS 17.0 (Breiman, 1984; De'ath and Fabricius, 2000) was used to characterise the relationships between LULC types, their area and the mean LST. Recently, the regression trees have been widely used in ecological studies to explore the interrelationships between different variables (Michaelsen et al., 1994; Rathert et al., 1999; Cardille and Clayton, 2007). It is a very useful technique with its tree structure and easy rule extraction. The most commonly used decision trees are called CHAID (Chi-Square Automatic Interaction Detector) by CART (Classification and Regression Trees) Analysis. Both are used for the same purposes and there are differences in the decision-making process. However, the CHAID method is generally more explanatory than the other method. For this purpose, in our case; CHAID analysis has been used as a regression tree analyses. CHAID is a sub-analysis within the classification and regression tree method. The CHAID method derives multiple trees and generally operates on the homogeneity of groups. This process can also provide normality and homogeneity in the distribution of data. In addition, continuous and categorical data can be included in the model with CHAID analysis (Şimşek and Şengezer, 2012).

According to this method that is used in this study, the independent variables that affect the dependent variable are first 
evaluated according to the values of explanatory variables (Özer et al., 2006). In the decision tree which consists of the nodes and branches; firstly the independent variables that are mostly affected from the dependent variables are defined, and then each independent variable are determined according to the degree of influence of the variables branching into sub-branches. In this study, while dependent variables were the LST values, the independent variables were the categories and size of the LULC types.

\section{RESULTS AND DISCUSSION}

\section{The Comparison of the LST with LULC Classes}

LST and meteorologic values for this period are shown in Table 5. LST result shows that LST maximum-minimum values are higher in June (48.59-22.46) and lower in September (34.92-12.6) The highest mean LST for the five Landsat scenes analyzed was $33.34{ }^{\circ} \mathrm{C}$ on June 19,2013 , and the lowest mean was $24.10^{\circ} \mathrm{C}$ on September 23, 2013 (Figure 3; Table 5).

The LST result shows that the maximum-minimum values of LST are higher in June $\left(48.59^{\circ} \mathrm{C}-22.46^{\circ} \mathrm{C}\right)$ and lower in September $\left(34.92^{\circ} \mathrm{C}-12.6^{\circ} \mathrm{C}\right)$ than the other two dates. The highest mean LST was $33.34{ }^{\circ} \mathrm{C}$ on June 19,2013 , and the lowest mean LST was $24.10^{\circ} \mathrm{C}$ on September 23, 2013 (Figure 3; Table 5).

When the basic descriptive relationships between the LST and different LULC types were examined by zonal statistics in ArcGIS, it was seen that the urban fabric has the highest LST maximum value with $48.60{ }^{\circ} \mathrm{C}$ in June, $47.11^{\circ} \mathrm{C}$ in July and $38.32{ }^{\circ} \mathrm{C}$ in August. This was followed by herbaceous vegetation associations, Agricultural areas and Industrial, commercial, public, military, private and transport units with $42.67{ }^{\circ} \mathrm{C}$ in June, $42.04{ }^{\circ} \mathrm{C}$ in July and $36.23{ }^{\circ} \mathrm{C}$ in May. On the other hand, the lowest LST value was found in Forest with $22.17{ }^{\circ} \mathrm{C}$ in August. Besides Water and Forest has the lowest mean LST value with $29.48^{\circ} \mathrm{C}$ in July, and has the highest mean value in Industrial, commercial, public, military, private and transport units in June with $36.0^{\circ} \mathrm{C}$.
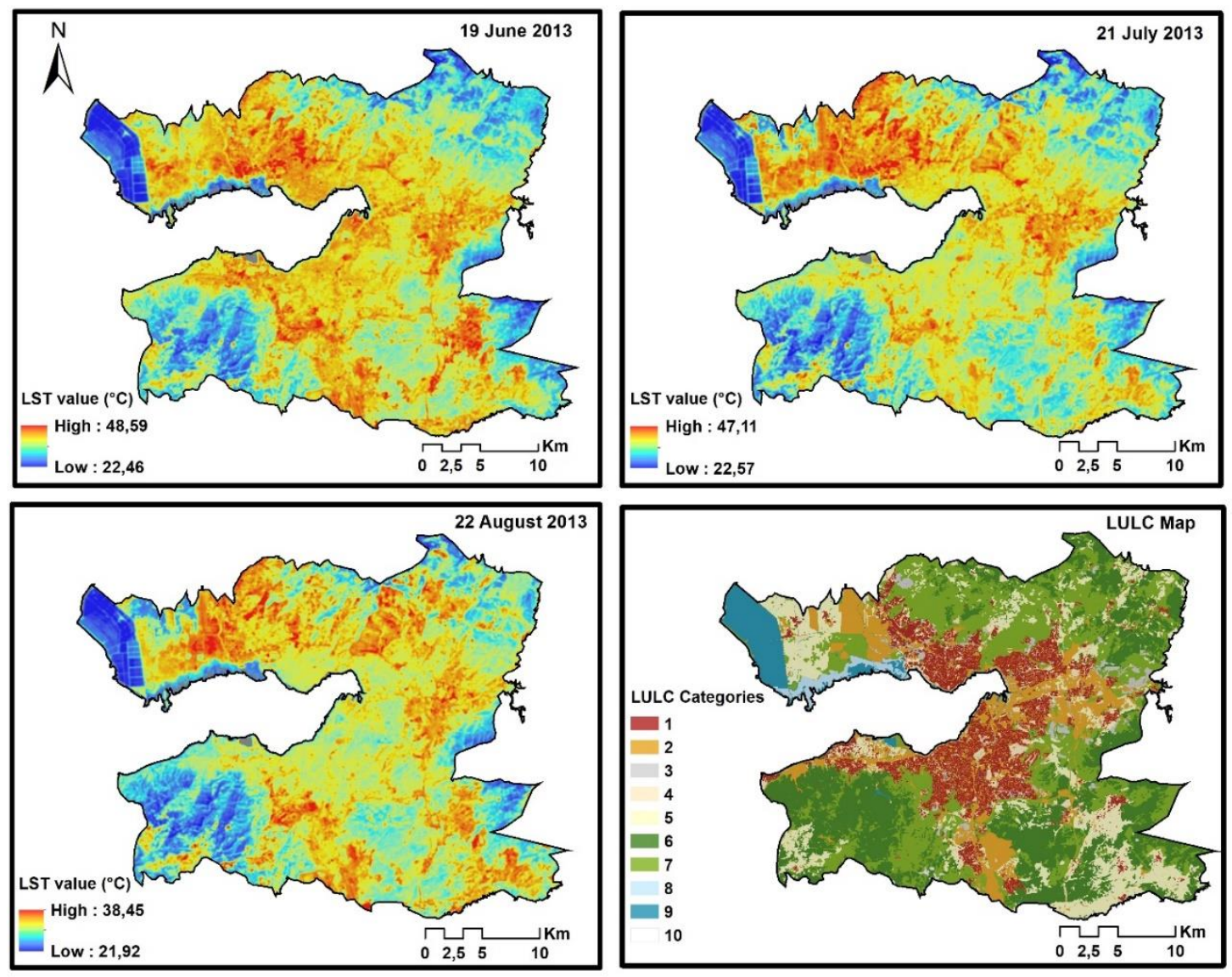

Figure 3: LST Maps for June, July and August 2013 and The Urban Atlas Land Use/Land Cover (LULC) Map of Izmir (LULC Categories; 1 Urban Fabric (1.1), 2 Industrial, commercial, public, military, private and transport units (1.2), 3 Mine, dump and construction sites (1.3), 4 Artificial non-agricultural vegetated areas (1.4), 5 Agricultural areas (2), 6 Forests (3.1), 7 Herbaceous vegetation associations (3.2), 8 Wetlands (4), 9 Water (5), 10 No data (Clouds and shadows (9.1)). 


\begin{tabular}{|c|c|c|c|c|c|c|c|c|c|c|c|c|}
\hline \multicolumn{13}{|c|}{ Table 5: LST Value for the Different LULC Classes } \\
\hline \multirow[b]{2}{*}{ ZONE_CODE } & \multicolumn{4}{|c|}{19 June 2013_LST $\left({ }^{\circ} \mathrm{C}\right)$} & \multicolumn{4}{|c|}{21 July 2013 LST $\left({ }^{\circ} \mathrm{C}\right)$} & \multicolumn{4}{|c|}{22 August 2013 LST $\left({ }^{\circ} \mathrm{C}\right)$} \\
\hline & Mın & Max & Range & Mean & Mın & Max & Range & Mean & Mın & Max & Range & Mean \\
\hline 1 & 25.22 & 48.60 & 23.38 & 35.89 & 25.64 & 47.11 & 21.48 & 34.95 & 23.61 & 38.32 & 14.71 & 30.64 \\
\hline 2 & 24.90 & 42.67 & 17.77 & 36.00 & 24.60 & 42.05 & 17.44 & 35.27 & 23.03 & 36.83 & 13.80 & 31.03 \\
\hline 3 & 26.76 & 40.82 & 14.06 & 34.82 & 26.39 & 42.34 & 15.95 & 34.13 & 23.71 & 36.62 & 12.91 & 29.74 \\
\hline 4 & 26.91 & 42.00 & 15.09 & 36.29 & 26.43 & 41.70 & 15.27 & 35.69 & 24.05 & 36.36 & 12.32 & 31.18 \\
\hline 5 & 25.32 & 42.74 & 17.43 & 34.98 & 25.90 & 42.21 & 16.31 & 34.32 & 23.82 & 37.93 & 14.11 & 30.71 \\
\hline 6 & 22.47 & 42.00 & 19.53 & 29.92 & 22.58 & 40.62 & 18.05 & 29.48 & 22.17 & 37.04 & 14.87 & 27.00 \\
\hline 7 & 22.82 & 44.24 & 21.42 & 33.92 & 24.31 & 44.22 & 19.91 & 34.04 & 22.61 & 38.46 & 15.85 & 30.67 \\
\hline 8 & 24.94 & 39.77 & 14.82 & 31.21 & 25.21 & 39.82 & 14.61 & 30.78 & 22.92 & 33.33 & 10.41 & 27.36 \\
\hline 9 & 22.68 & 40.81 & 18.13 & 26.03 & 23.60 & 40.43 & 16.83 & 26.67 & 21.93 & 34.05 & 12.12 & 24.03 \\
\hline 10 & 28.06 & 35.84 & 7.78 & 30.83 & 27.29 & 35.18 & 7.89 & 30.34 & 25.89 & 32.42 & 6.52 & 28.19 \\
\hline Study area_LST & 22.47 & 48.59 & 26.12 & 33.34 & 22.58 & 47.11 & 24.53 & 32.83 & 21.92 & 38.45 & 16.53 & 29.35 \\
\hline 1 Urban Fabric & $2 \ln$ & Istrial, co & ercial, 1 & c, milit & & & & & & struc & sites ( & \\
\hline
\end{tabular}

The withering of plants which was resulted in bare soil surface was thought to be a reason for having the above mentioned results for the selected months. On the other hand, when the average LST values were examined, it was found that the urban fabric were in the 3th place following the areas where the plant presence was quite low (such as Industrial, commercial, public, military, private and transport units and artificial non-agricultural vegetated areas). The highest temperature difference between the LST and LULC types was observed in urban fabrics in June and July, and in herbaceous vegetation associations in August. Because of the drying and openings in herbaceous vegetation associations in this month, the surface temperature dramatically increased. According to a research conducted by Murphy et al. (2011); it was implied that the highest temperature difference was found between urban fabric and forest compared with herbaceous vegetation association. Herbaceous vegetation are ineffective in combating daytime warming, while tree cover and shadows are successful in reducing daytime warming. Contrary to what is believed, this result also shows that the effect of herbaceous plants is never as effective as woody plants.

The average LST values of these LULC types $\left(33.34^{\circ} \mathrm{C}, 32.83^{\circ} \mathrm{C}\right.$ and 29.35 , for selected months respectively) show us that the presence of plants and water reduces the UHI effect in urban areas. On the other hand, when the mean and maximum LST values were evaluated together, it was concluded that the green areas in between the buildings decrease the UHI effect, but the drying of and openings in the herbaceous vegetation associations increases UHI effect. Consequetly, it is clearly demonstrate that green areas are reduce the surface temperature in the hottest months.

\section{The Relationship between LST and LULC Classes Using Regression Tree}

In order to better evaluate the relationships between the LST and LULC types, CHAID Regression Tree method has been was seperately applied for the selected tree months. According to results obtained by regression tree; the mean LST value in June is $35.37^{\circ} \mathrm{C}$. At the top of the regression tree diagram, Node 0 , which give the general descriptive statistics of the mean LST value, is divided into new two child nodes. Node 1 represents that the LULC classes; the herbaceous vegetation associations; forest; agriculture; wetlands and Nodata_cloud is the lowest LST values $\left(26.08{ }^{\circ} \mathrm{C}\right)$ compared to the Node2. Node 2 represents that the Industrial, commercial, public, military, private and transport units; Mine, dump and construction sites; water; artificial non-agricultural vegetated areas have the highest LST values $\left(28.14^{\circ} \mathrm{C}\right)$. In Node 1 , the LULC types are divided into tree new child nodes, including herbaceous vegetation associations; wetlands (Node3), forest; Nodata_cloud (Node4) and agriculture classes (Node5). In these nodes, whilst the agricultural areas have the highest LST value, the lowest LST values are found in forest and cloud areas.

The result also showed that the area of the LULC types affected the LST values. There is a negative correlation between the size of the herbaceous vegetation associations; wetlands, forest; Nodata_cloud, agricultural areas, and the LST values. When the size get larger, the LST values get lower. However, in Node 2, the LULC types are divided into four child node including Industrial, commercial, public, military, private and transport units (Node6); urban fabrics (Node7); mine, dump and construction sites (Node8); artificial non-agricultural vegetated areas (Node9). Mine, dump and construction sites reported the highest LST values, but in urban areas the LST values are the lowest. The other child nodes show that there is a positive correlation between the LST and the size of LULC types from Node 6 to Node 8. When the size get larger, the LST values are higher. On the contrary, when the size of artificial non-agricultural vegetated areas including open spaces and urban green spaces (Node9) are larger, the LST values are lower. In general, the LST values are the lowest in wetlands and forest with larger area sizes. On the other hand, mine, dump and construction sites covered large areas have the highest LST value.

The mean LST value in July is $34.32^{\circ} \mathrm{C}$ and the general descriptive statistics of the LST mean value, is divided into new two 
child nodes as in June. Node 1 represents that the LULC types; herbaceous vegetation associations; agriculture; industrial, commercial, public, military, private and transport units, Urban fabrics; Mine, dump and construction sites; Water; artificial non-agricultural vegetated areas reported the highest LST values $\left(34.40^{\circ} \mathrm{C}\right)$ compared to the Node2. Node 2 represents that the forest; wetlands; Nodata_cloud have the lowest LST values $\left(31.20^{\circ} \mathrm{C}\right)$. In Node 1 , LULC types are divided into four child node including herbaceous vegetation associations, water (Node3); agriculture, industrial, commercial, public, military, private and transport units, artificial non-agricultural vegetated areas (Node4); urban fabrics (Node5); mine, dump and construction sites (Node6). In these nodes, mine, dump and construction sites (Node6) is the highest LST value, whilst herbaceous vegetation associations, water (Node3) have the lowest values.

The result also show that the size of the LULC types affects the LST values. When the size of the mine, dump and construction sites (node6), urban fabrics (Node5) increased, the LST values become higher. But there is a negative correlation between the size of the herbaceous vegetation associations; water and the LST values. When the size get larger, the LST values get lower. In Node 2, the LULC types were divided into two child nodes according to the area of LULC types in Node 7 and Node 8. When the area of the forest; wetlands are larger, the LST values are lower. July and June have a similar patterns of LST.

The mean LST value in August was $30.18^{\circ} \mathrm{C}$ and the general descriptive statistics of the mean LST valuewas divided into new two child nodes. Node 1 represents that the LULC classes; herbaceous vegetation associations; forest; urban_areas; Water; Artificial non-agricultural vegetated areas; Wetlands; Nodata_cloud had the lowest LST values $\left(29.96^{\circ} \mathrm{C}\right)$ compared to the Node2. Node 2 represents that the agriculture; Industrial, commercial, public, military, private and transport units; Mine, dump and construction sites areas have the highest LST values $\left(30.81^{\circ} \mathrm{C}\right)$. In Node 1 , the LULC types are divided into four child node including herbaceous vegetation associations, artificial non-agricultural vegetated areas (Node3), forest; Nodata_cloud (Node4), urban fabrics (Node5) and Water, Wetlands (Node 6). Herbaceous vegetation associations, artificial non-agricultural vegetated areas (Node3) and urban fabrics (Node5) are the highest LST values. With the high percentage of the other LULC types in these four Nodes, urban fabrics are also divided into four child nodes according to their area. When the size of the urban area increased, the LST values are also increased. In Node 2, the LULC types are divided into three child node depending on the size of LULC classes in this node. When the size of Agriculture; Industrial, commercial, public, military, private and transport units; Mine, dump and construction sites areas are increased, the LST values are increased. The other child nodes show that covering large areas, mine, dump and construction sites are the highest LST values. When the size of the Industrial, commercial, public, military, private and transport units are low, the LST values are the lowest.

In summer period, izmir has higher temperatures in the artificial surfaces (such as mine, dump and construction sites, urban fabric, industrial, commercial, public, military, private and transport units) and lower temperatures in the forest and water.

The size of the LULC types is also an important factor that affects the temperature of land surfaces. Depending on the type of present LULC, the LST value represents different trends (positive or negative correlation). For example, if vegetation surfaces get larger, the value of LST decreases, but, if artificial surfaces inrease, the LST values increase.

General result obtained from this research is represent that the type of the vegatation is also effective to change the land surfaces temperature. There is a different reflection between woody plant (forest etc.) and grassland (herbaceous vegetation etc.) in summer monts. For that reason, when planning and designing urban landscapes, we should consider that the selection of appropriate plant species is another important factor to decrease the surface temperature. Surface temperature of agricultural areas and herbaceous vegetation associations are varied depending on seasonal transitions. While agricultural areas and herbaceous vegetation associations are lowest LST value in June, highest in July and August as well as urban fabrics.

When the basic descriptive relationships between the LST and different LULC types are evaluated, mine, dump and construction sites have the third or fourth highest mean LST values comparing the other LULC types. Because, its size and patch number is lower comparing with other LULC classes. Even though the size of a LULC type is small, its surface temperature can be higher and more effective than the larger ones. Since the regression analysis compares the differences between the groups and makes the calculations taking into account the number of parcels (patch number) and area of LULC, it provides clear information about the landscape in general. In addition to this, the regression tree method is very flexible and powerful tool to identify and quantify complex relationships between LST and LULC. It is also easy to interpret and express interactions between variables. 


\section{CONCLUSION}

Urban LULC changes are considered to be an important driving force in landscape change at all temporal and spatial scales, and it is also one of the most important factors that adversely effects the landscape and urban climate. The LST has critical importance in urban climatical research, since it helps researchers to understand its causes and also effects on environmental conditions not only for human beings but also for other living organisms in natural and cultural ecosystems. Therefore, a better understanding of how LULC dynamics affect the LST is crucial for landscape planning and management. Accordingly, in this study, the LST has been calculated to determine UHI effect in İzmir. Additionally, regression tree analysis has been used to understand which LULC types are strongly correlated with LST.

The regression tree analyses results show that LST values were increased with the increasing proportion of artificial surfaces (e.g. urban fabric, Industrial, commercial, public, military, private and transport units, mine, dump and construction sites, artificial non-agricultural vegetated areas) and sharply decreasing proportion of green space (in particular in forests, water resources and wetlands) for the selected three months. It is also found that there is a strong positive correlation between the LST values and mine, dump and construction sites. Mine, dump and construction sites are the highest LST value for all the selected tree months. It is conspicuous, because, mine, dump and construction sites have become one of the major problems in Izmir. Mines and dump sites are growing day by day and spreading in all around in Izmir. This research showed that such land uses not only destruct the natural and cultural landscape elements, but also increase the land surface temperature and adversely affect the urban climate regardless of their sizes in the whole landscape. Besides, the LST values were the lowest in wetlands and forest with a large areas. It means that the artificial surfaces trigger the formation of UHIs in the summer months when the air temperature was the highest, but the presence of vegetation, water and wetlands can help to reduce this negative effect. As the area of green areas and tree communities expands, the degree of UHIs effect also decreases.

When the LST values in the study area were examined spatially (Figure 3), it was found that even the presence of single trees and small proportions of plant surfaces within the settlements, can help to reduce the UHI effect. Akbari (2002) indicate that the planted trees in urbinised areas have a significant positive effect on healing the ozone air quality and cooling the air. That is simply a result of the biophysical properties of green areas which are one of the most prominent parameters in healing the urban climate. The shading and evaporation process of forests are the natural cooling mechanism in urban areas. So, the results of this researh also supported that the forests are the coolest areas in urban areas. Therefore, in order to reduce the UHI effect in urban areas, it is necessary to plant refuges, to support afforestation and to increase the amount of urban green areas (Önder and Akay, 2014). In the cases where these suggestions cannot be realised (for example, in densely populated areas and areas where the existing land use patterns cannot be changed), increasing the existing plant assets through green roof and wall systems, or using appropriate surface material which can reduce the temperature would play an important role in reducing the UHI effects in cities (Golden, 2004). As a result, the development of proposals that can reduce the occurrence of UHI effect examples presented in this study would guide planners, designers and decision-making mechanisms in landscape planning and design studies. Although the concept of the UHI effect has been the subject of many researches, it is still an element that the local governments ignore in landscape planning and management. Additionally, a strategy to optimize the most significant LULC types to minimize the UHI effect is still defective. Therefore, analysis of the adverse effects of UHI created by particular LULC types can help us to take measures to minimize UHI effect and to develop strategies. For example, protection of the natural flora of a city and its surrounding areas could help us to create healthy and livable cities. Besides, the establishment of the urban green systems should be considered as part of the landscape planning system in Turkey instead of having patchy urban green spaces without knowing their functioning in the whole city.

\section{ACKNOWLEDGEMENTS}

This research did not receive any specific grant from funding agencies in the public, commercial, or not-for-profit sectors.

\section{References}

Akbari, H. \& Kolokots, D. (2016). Three decades of urban heat islands and mitigation technologies research. Energy and Buildings, 133 ,

834-842.

Alexandri, E. \& Jones, P. (2008). Temperature decreases in an urban canyon due to green walls and green roofs in diverse climatesournal of Agricultural Engineering, 3(1), 1-5.

Building and Environment, 43(4), 480-493.

Alghannam, A. R. O. \& Al-Qahtnai, M. R. A. (2012). Impact of vegetation cover on urban and rural areas of arid climates. Australian 
Aydın, M. B. S., Erdin, H. E. \& Kahraman, E. D. (2017). Mekansal yapı özellıklerı açısından iklım değışıklığıne karşı rısk taşıyan bölgelerin saptanması. İmir Planlama, 27(3), 274-285.

Barsi, J. A., Schott, J. R., Palluconi, F. D. \& Hook, S. J. (2005). Validation of a web-based atmospheric correction tool for single thermal band instruments. Proceedings, 5882, 16-33.

Breiman, L., Friedman, J., Olshen, R. \& Stone, C. (1984). Classification and regression trees. Wadsworth Int. Group, 37(15), $237-251$.

Cardille, J. \& Clayton, M. K. (2007). A regression tree-based method for integrating land-cover and land-use data collected at multiple scales. Environmental and Ecological Statistics, 14(2), 161-179.

Chander, G. \& Markham, B., (2003). Revised Landsat-5 TM radiometric calibration procedures and postcalibration dynamic ranges. IEEE Transactions on Geoscience and Remote Sensing, 41(11), 2674-2677.

Chen, A., Yao, X. A., Sun, R. \& Chen, L. (2014). Effect of urban green patterns on surface urban cool islands and its seasonal variations. Urban forestry \& urban greening, 13(4), 646-654.

CLMS, (2018). Copernicus Land Monitoring Service, Imperviousness. Retrieved July 5, 2018, from https://land.copernicus.eu/local/urban-atlas/urban-atlas-2012.

De'ath, G. \& Fabricius, K. E. (2000). Classification and regression trees: a powerful yet simple technique for ecological data analysis. Ecology, 81(11), 3178-3192.

Du, H., Cai, W., Xu, Y., Wang, Z., Wang, Y. \& Cai, Y. (2017). Quantifying the cool island effects of urban green spaces using remote sensing data. Urban Forestry and Urban Greening, 27, 24-31.

Du, H., Wang, D., Wang, Y., Zhao, X., Qin, F., Jiang, H. \& Cai, Y. (2016). Influences of land cover types, meteorological conditions, anthropogenic heat and urban area on surface urban heat island in the Yangtze River Delta Urban Agglomeration. Science of the Total Environment, 571, 461-470.

EEA, (2012). European Environment Agency, Urban Atlas Data Programme. Retrieved 20 May, 2018 from http: //land.copernicus.eu/local/urban-atlas/

EPA, (2012). Measuring Heat Islands, State and Local Climate and Energy Program, Heat Island Notes.

Ersoy, E., (2019). Landscape Pattern and Urban Cooling Islands. Fresenius Environmental Bulletin, 28(3), 1943-1951.

Feizizadeh, B., Blaschke, T., Nazmfar, H., Akbari, E. \& Kohbanani, H.R. (2013). Monitoring land surface temperature relationship to land use/land cover from satellite imagery in Maraqeh County, Iran. Journal of Environmental Planning and Management, 56(9), 1290-1315.

Golden, J.S. (2004). The built environment induced urban heat island effect in rapidly urbanizing arid regions-a sustainable urban engineering complexity. Environmental Sciences, 1(4), 321-349.

Hart, M.A. \& Sailor, D.J. (2009). Quantifying the influence of land-use and surface characteristics on spatial variability in the urban heat island. Theoretical and Applied Climatology, 95(3-4), 397-406.

Huang, L., Zhao, D., Wang, J., Zhu, J. \& Li, J. (2008). Scale impacts of land cover and vegetation corridors on urban thermal behavior in Nanjing, China. Theoretical and Applied Climatology, 94(3-4), 241-257.

Jimenez-Munoz, J.C. \& Sobrino, J.A. (2010). A single-channel algorithm for land surface temperature retrieval from ASTER data. IEEE Geoscience and Remote Sensing Letters 7(1): 176-179

Klein, P.M. \& Coffman, R. (2015). Establishment and performance of an experimental green roof under extreme climatic conditions. Science of the Total Environment, 512, 82-93.

Markham, B.L. \& Barker, J.L. (1985). Spectral Characterization of the Landsat Thematic Mapper Sensors. International Journal of Remote Sensing, 6, 697-716.

Michaelsen, J., Schimel, D.S., Friedl, M.A., Davis, F. W. \& Dubayah, R.C. (1994). Regression tree analysis of satellite and terrain data to guide vegetation sampling and surveys. Journal of Vegetation Science, 5(5), 673-686.

Montávez, J.P., Rodríguez, A. \& Jiménez, J.I. (2000). A study of the urban heat island of Granada. International Journal of Climatology, 20(8), 899-911.

Murphy, D. J., Hall, M. H., Hall, C. A. S., Heisler, G. M., Stehman, S. V. \& Molina, C. A. (2011). The relationship between land cover and the urban heat island in northeastern Puerto Rico. International Journal of Climatology, 31(8), 1222-1239.

Nieuwolt, S. (1966). The urban microclimate of Singapore. Journal of Tropical Geography, 22(6), 30-37.

Nurlu, E., Kesgin Atak, B. \& Barut, I. (2015). Analyzing the Degree of Landscape Fragmentation in Izmir, Turkey from 1984 to 2009 . In R. Efe, C. Bizzarri, i. Cürebal \& G. N. Nyusupova (Eds.), Environment and Ecology at the Beginning of 21st Century (pp.545-555). St. Kliment Ohridski University Press. ISBN 978-954-07-3999-1

Oguz, H. (2013). LST Calculator: a program retrieving land surface temperature from Landsat TM/ ETM+ Imagery. Environmental Engineering and Management Journal, 12(3): 549-555

Oguz, H. (2015). A software tool for retrieving land surface temperature from aster imagery. Journal of Agricultural Sciences, 21(4), 471-482.

Oke, T. R. (1973). City size and the urban heat island. Atmospheric Environment (1967), 7(8), 769-779. 
Önder, S. \& Akay, A. (2014). The roles of plants on mitigating the urban heat islands' negative Effects. International Journal of Agriculture and Economic Development, 2(2), 18.

Özer, O. O., Yavuz, G. G. \& Gül, U. (2016). Demographic factors influencing consumer preferences of seafood consumption: Central Anatolia Region. Turkish Journal of Agriculture-Food Science and Technology, 4(5), 356-364.

Pal, S. \& Ziaul, S.K. (2017). Detection of land use and land cover change and land surface temperature in English Bazar urban centre. The Egyptian Journal of Remote Sensing and Space Science, 20(1), 125-145.

Price, J.C. (1984). Land surface temperature measurements from the split window channels of the NOAA 7 Advanced Very High Resolution Radiometer. Journal of Geophysical Research: Atmospheres, 89(D5), 7231-7237.

Rathert, D., White, D., Sifneos, J. C. \& Hughes, R. M. (1999). Environmental correlates of species richness for native freshwater fish in Oregon, USA. Journal of Biogeography, 26(2), 257-273.

Reddy, S. N. \& Manikiam, B. (2017). Land surface temperature retrieval from LANDSAT data using emissivity estimation. International Journal of Applied Engineering Research, 12(20), 9679-9687.

Rozenstein, O., Qin, Z., Derimian, Y. \& Karnieli, A. (2014). Derivation of land surface temperature for Landsat-8 TIRS using a split window algorithm. Sensors, 14(4), 5768-5780.

Şahin, M., Yildiz, B. Y., Şenkal, O. \& Peştemalci, V. (2011). Uydu verileri kullanılarak Izmir şehir merkezinin yer yüzey sıcaklığının tahmini. Süleyman Demirel Üniversitesi Fen-Bilimleri Enstitüsü Dergisi, 15(1), 36-45.

Santamouris, M., Cartalis, C., Synnefa, A. \& Kolokotsa, D. (2015). On the impact of urban heat island and global warming on the power demand and electricity consumption of buildings - A review. Energy and Buildings, 98, 119-124.

Schwarz, N., Schlınkb, U., Franckb, U. \& Großmannc, K. (2012). Relationships of land surface and air temperature and its implications for quantifying urban heat island indicators - An application for the city of Leipzig (Germany). Ecological Indicators, 18, 693704

Şimşek, Ç. K. \& Şengezer, B. (2012). İstanbul metropoliten alaninda kentsel isinmanin azaltilmasinda yeşil alanlarin önemi. Megaron $7(2), 116-128$

Sobrino, J. A., Jiménez-Muñoz, J. C. \& Paolini, L. (2004). Land Surface Temperature Retrieval from LANDSAT TM 5. Remote Sensing and Environment, 90(4), 434-440.

Stone, B. \& Norman, J. M. (2006). Land use planning and surface heat island formation: A parcel-based radiation flux approach. Atmospheric Environment, 40(19), 3561-3573.

Streutker, D. R. (2003). A study of the urban heat island of Houston, Texas. (Doctoral dissertation, Rice University).

Tonyaloğlu, E. E. (2019). Kentleşmenin kentsel termal çevre üzerindeki etkisinin değerlendirilmesi, efeler ve İncirliova (Aydın) örneği. Türkiye Peyzaj Araştırmaları Dergisi, 2(1), 1-13.

Tran, H., Uchihama, D., Ochi, S. \& Yasuoka, Y. (2006). Assessment with satellite data of the urban heat island effects in Asian mega cities. International journal of Applied Earth Observation and Geoinformation, 8(1), 34-48.

TUIK, (2019). Turkish Statistical Instute. Retrieved Feburary 15, 2019 from http://www.tuik.gov.tr/PreTablo.do?alt_id=1047

USGS, (2018). The United States Geological Survey. Landsat 8 Data Users Handbook - Section 5. Retrieved July 7, 2018, from https://landsat.usgs.gov/landsat-8-/8-data-users-handbook-section-5

Valsson, S. \& Bharat, A. (2009). Urban heat island: Cause for microclimate variations. Architecture-Time Space \& People, 2125.

Voogt, J.A. \& Oke, T.R. (2003). Thermal remote sensing of urban climates. Remote Sensing of Environment, 86(3), 370-384.

Wan, Z., Wang, P. \& Li, X. (2004). Using MODIS land surface temperature and normalized difference vegetation index products for monitoring drought in the southern Great Plains, USA. International Journal of Remote Sensing, 25(1), 61-72.

Weng, Q., Lub, D. \& Schubrınga, L. (2004). Estimation of land surface temperature-vegetation abundance relationship for urban heat island studies. Remote Sensing of Environment, 89, 467-483.

Xiao, H., Kopecká, M., Guo, S., Guan, Y., Cai, D., Zhang, C. \& Yao, W. (2018). Responses of urban land surface temperature on land cover: A comparative study of Vienna and Madrid. Sustainability, 10(2), 260.

Yavaşli, D. D., Ölgen, M. K. \& Zoğal, V. (2018). Are summer resorts cooler in summer? A case study of İzmir province. Ege Coğrafya Dergisi, 27(2), 127-134.

Yuan, F. \& Bauer, M.E. (2007). Comparison of impervious surface area and normalized difference vegetation index as indicators of surface urban heat island effects in Landsat imagery. Remote Sensing of Environment, 106(3), 375-386.

Zhao, W., Li, A.N. \& Zheng, J. (2016). A study on land surface temperature terrain effect over mountainous area based on Landsat 8 thermal infrared data. Remote Sensing Technology and Application, 31(1), 63-73

Zhou, W. Q., Qian, Y.G., Li, X. M., Li, W. F. \& Han, L. J. (2014). Relationships between land cover and the surface urban heat island: seasonal variability and effects of spatial and thematic resolution of land cover data on predicting land surface temperatures. Landscape Ecology. 29, 153-167. 